Scientific Electronic Archives

Issue ID: Sci. Elec. Arch. Vol. 14 (12)

December 2021

DOI: http://dx.doi.org/10.36560/141220211477

Article link: https://sea.ufr.edu.br/SEA/article/view/1477

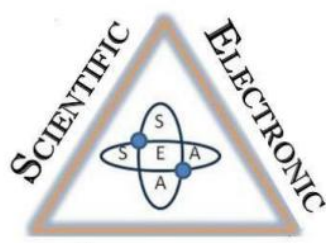

ArChives

ISSN 2316-9281

\title{
Uso de plantas medicinais no bairro Liberdade, município de Breu Branco - Pará
}

\author{
Use of medicinal plants in the Liberdade neighborhood, municipality of Breu \\ Branco - Pará
}

\author{
Luciana Rodrigues Duarte \\ Instituto Federal do Pará
}

\author{
Corresponding author \\ Sandro Dan Tatagiba \\ Instituto Federal do Pará \\ sandrodantatagiba@yahoo.com.br
}

\begin{abstract}
Resumo. O uso das plantas para fins medicinais é uma prática cultural, desenvolvida e modificada entre diversas populações, com especificidades em cada região do país. Dessa forma, o presente estudo teve como objetivo, investigar as espécies botânicas medicinais de acordo a utilização local, formas de uso, indicação de uso, preparo e formas de obtenção, a fim de validar as plantas principais plantas com indicação etnofarmacológica, no bairro Liberdade no município de Breu Branco, estado do Pará. Foram coletadas informações de 50 informantes, todos moradores locais, selecionados aleatoriamente, por meio de entrevista semi-estruturadas, observações participativas e visitas guiadas. Foram identificadas 39 espécies botânicas medicinais, pertencentes 29 famílias. A família Lamiaceae apresentou o maior número de espécies citadas, com cinco espécies mencionadas, seguido das famílias Apiaceae, Malvaceae e Poaceae, com três espécies cada. A folha foi à parte da planta mais utilizada, enquanto o hábito de crescimento herbáceo o mais encontrado entre as espécies de plantas, sendo o chá da folha o procedimento mais comum usado para preparar medicamentos. As mulheres foram às principais responsáveis pelo cultivo das espécies, preparação do medicamento e repasse de conhecimento relativo às plantas. Os sintomas inflamatórios foram os mais indicados para o tratamento fitoterápico. As espécies mais citadas pelos informantes foram: Melissa officinalis, Plectranthus barbatus, Mentha spicata e Cymbopogon atratus, indicando ser as mais promissoras para a realização de estudos farmacológicos no combate a enfermidades.
\end{abstract}

Palavras-chaves: Etnobotânica, flora medicinal, uso tradicional.

Abstract. The use of plants for medicinal purposes is a cultural practice, developed and modified among different populations, with specificities in each region of the country. Thus, the present study aimed to investigate the medicinal botanical species according to local use, forms of use, indication of use, preparation and forms of obtaining, in order to validate the main vegetable plants with ethnopharmacological indication, in the district of. Freedom. In the municipality of Breu Branco, State of Pará, information was collected from 50 informants, all local residents, randomly selected through semi-structured interviews, participatory observations and guided tours. 39 medicinal botanical species were identified, belonging to 29 families. The Lamiaceae family had the highest number of cited species, with five cited species, followed by the Apiaceae, Malvaceae and Poaceae families, with three species each. The leaf was the most used part of the plant, while the herbaceous growth habit was the most found among plant species, with leaf tea being the most common procedure in the preparation of medicines. Women were primarily responsible for cultivating the species, preparing medicines and transmitting knowledge related to plants. Inflammatory symptoms were the most indicated for herbal treatment by the informants. The species most cited by the informants were Melissa officinalis, Plectranthus barbatus, Mentha spicata and Cymbopogon atratus, which indicates that they are the most promising for carrying out pharmacological studies in combating diseases.

Keywords: Ethnobotany, medicinal flora, traditional use.

\section{Introdução}

Compreender as relações do homem com as espécies vegetais tornou-se de grande utilidade para humanidade, já que muitas comunidades possuem relações duradoura e mútua com os vegetais, desenvolvendo sistemas de manejos únicos (Albuquerque; Andrade, 2002). O vínculo criado entre $o$ homem $e$ as plantas, tornou-os 
principais indivíduos de preservação da biodiversidade vegetal, que podem ser aproveitadas para a fabricação de medicamentos, alimentos e artesanato (Silva, 2014). Desse modo, a etnonotânica é a ciência que auxilia na análise dos conhecimentos populares que o homem possui sobre o uso das plantas. É por meio dos estudos realizados que se evidencia o perfil de uma comunidade e suas relações com as espécies vegetais, pois cada comunidade tem e especificidades, visando conhecer informações que possam ser favoráveis sobre usos de plantas medicinais (Martins et al. 2005).

Pesquisas dessa natureza tendem a colaborar com o diálogo entre as comunidades e o poder público para o desenvolvimento de práticas de conservação das tradições populares em ambientes urbanos ou rurais e a exploração sustentável das plantas medicinais, dada a carência de ferramentas de aproximação entre os discursos e a efetivação jurídico-política (Rocha; Boscolo; Fernandes, 2015; Rocha; Neffa; Leandro, 2014).

Apesar de levantamentos etnobotânicos serem associados aos povos tradicionais, essa realidade foi modificada pela urbanização, e em meio as mudanças heterogêneas perduram-se os traços culturais em sociedades em constante transformação. Novos hábitos da vida urbana vão inserindo-se, na dinâmica cultural das cidades, mas não necessariamente extinguem a realidade anterior, vividos pelos moradores nativos (Gandolfo; Hanazaki, 2011). O desenvolvimento urbano é um fator de alterações das tradições populares, a compressão das relações das comunidades urbanas com as plantas pode auxiliar em estudos químicos e farmacológicos.

Desta forma, torna-se interessante investigar como são utilizadas as espécies medicinais de localidades urbanas na região norte brasileira, ainda pouco explorada. Nesse sentido, atentando-se a importância dos registros etnobotânicos para conhecer a variedade da flora medicinal e os poucos estudos realizados no norte paraense, região banhada pelo Rio Tocantins, o presente estudo teve como objetivo, realizar o levantamento das espécies botânicas medicinais de acordo a utilização local, identificar as formas de uso, indicação, preparo, formas de obtenção, e por fim, validar as plantas com indicação etnofarmacológica, do bairro Liberdade no município de Breu Branco, estado do Pará.

\section{Material e Métodos}

Área de estudo

O estudo foi realizado no município de Breu Branco (Figura 01) localizado no sudeste paraense, a $320 \mathrm{~km}$ da capital do Estado, possuindo extensão territorial de $3.941,908 \mathrm{~km}^{2}$ e uma população estimada em 67.332 pessoas no ano de 2020 (IBGE, 2017). O município originou-se as margens do Rio Tocantins, após a inundação da antiga vila denominada, Breu Velho, ao qual ainda era pertencente ao território do município de Tucuruí, desvinculando-se no ano de 1991. O nome da cidade associa-se a árvore nativa, que produz uma resina característica para a fabricação do breu. $\mathrm{O}$ clima tropical da região registra temperatura média relativa entre 26 a 32 Co, com vegetação essencialmente amazônica, subdivida em igapó, várzea e mata firme, apresentado intensos níveis de desmatamento, decorrentes da exploração da floresta (IBGE, 2017).

Em virtude da inundação da Vila de Breu Velho, a população foi transferida para terras a 12 $\mathrm{km}$ da hidrelétrica de Tucuruí, as margens da rodovia PA 263, ocorrendo de forma lenta e conflituosa, decorrente aos atrasos da infraestrutura da nova localidade. Ainda no período do remanejamento da população que ocupava a antiga Vila de Breu Velho, para o atual município de Breu Branco, possuía-se alguns bairros planejados e construídos pelas Centrais Elétricas do Norte do Brasil S/A (Eletronorte), mas foram insuficientes para os habitantes, e com o aumento populacional local, iniciou-se invasões de terras, fundando-se o bairro Liberdade (Figura 02), localizado a direita da PA 263 (Prefeitura de Breu Branco, 2006).

A invasão territorial onde hoje está localizado o atual bairro Liberdade ocorreu em terras privadas de um fazendeiro local e pertencentes a Associação de Serrarias do município de Breu Branco no ano 2000. Embora, a falta de planejamento, estruturação e conflitos pela recuperação das terras ocorridos nos primeiros anos após a invasão local onde hoje encontra-se o bairro Liberdade, atualmente encontra-se estruturado e desenvolvimento, possuindo o reservatório de captação de água do município, duas escolas de ensino infantil e fundamental, uma unidade de saúde em construção, supermercados, churrascaria, campo society, posto de gasolina, igrejas, bares, lojas de materiais de construção e produtos agropecuários, além de oficinas para veículos, uma jazida e dezenas de outros empreendimentos. Contudo, apesar da expansão comercial e populacional ocorrida nos últimos anos, ainda há falta e carência de saneamento básico (Levantamento realizado pela autora).

Aspectos éticos e legais da pesquisa

O estudo foi aprovado pelo Comitê de Ética em Pesquisa (CEP) da Universidade Estadual do Pará, Campus VIII, localizada no município de Marabá, obtendo aval sob CAEE 43883621.9.0000.8607 e número de parecer 4.604.581, aprovado dentro dos princípios éticos e da legislação vigente. Antes de iniciar o estudo foram realizadas visitas ao bairro, almejando 0 conhecimento das singularidades socioculturais da população, além de informar o obejtivo e as metas do trabalho, além de convidar a população ára participae do estudo. Aqueles informantes que concordaram em fazer parte da pesquisa assinaram o Termo de Consentimento Livre Esclarecido (TCLE), conforme preconizam as diretrizes da resolução nํㅜ 466/12 do Conselho Nacional de Saúde (BRASIL, 2013). 


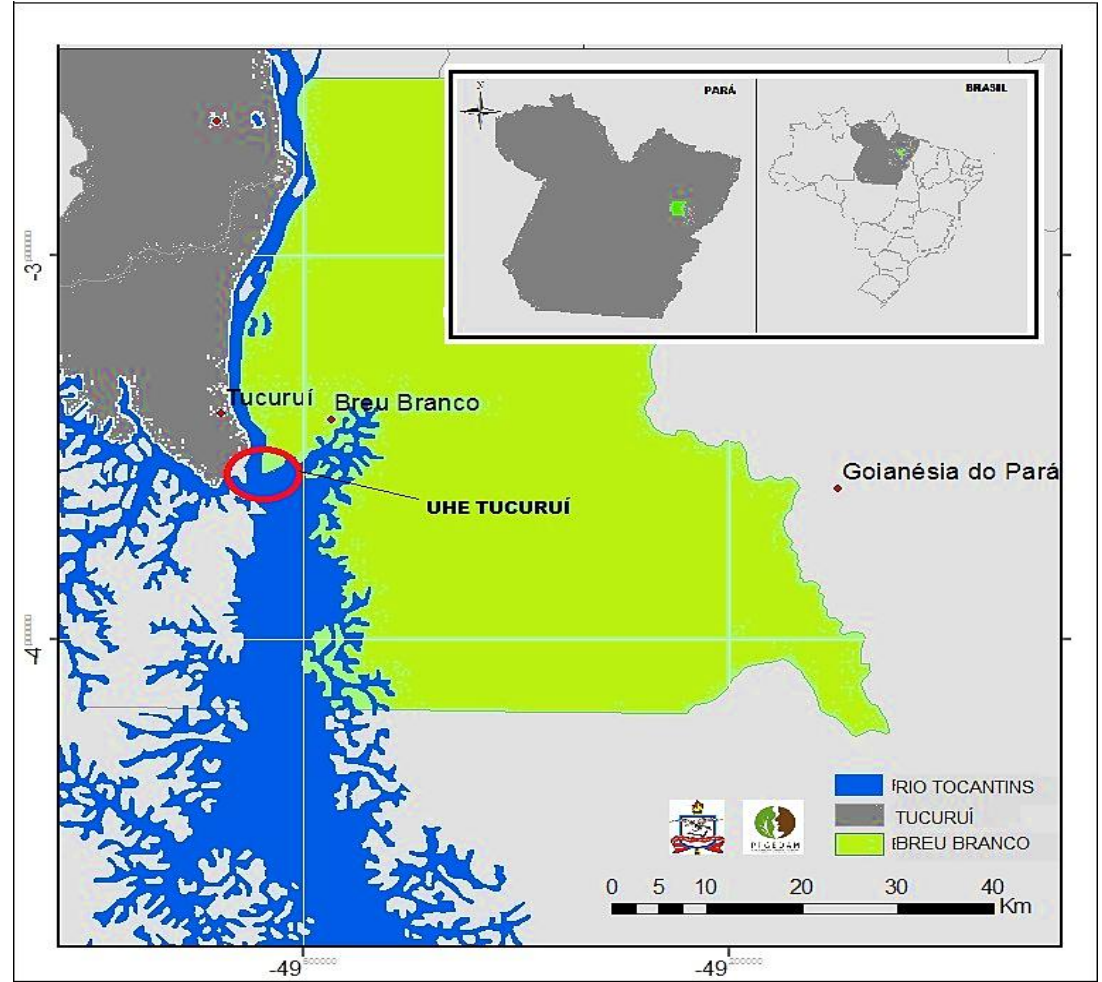

Figura 01. Localização do município de Breu Branco, estado do Pará. Fonte: Silva, 2019.

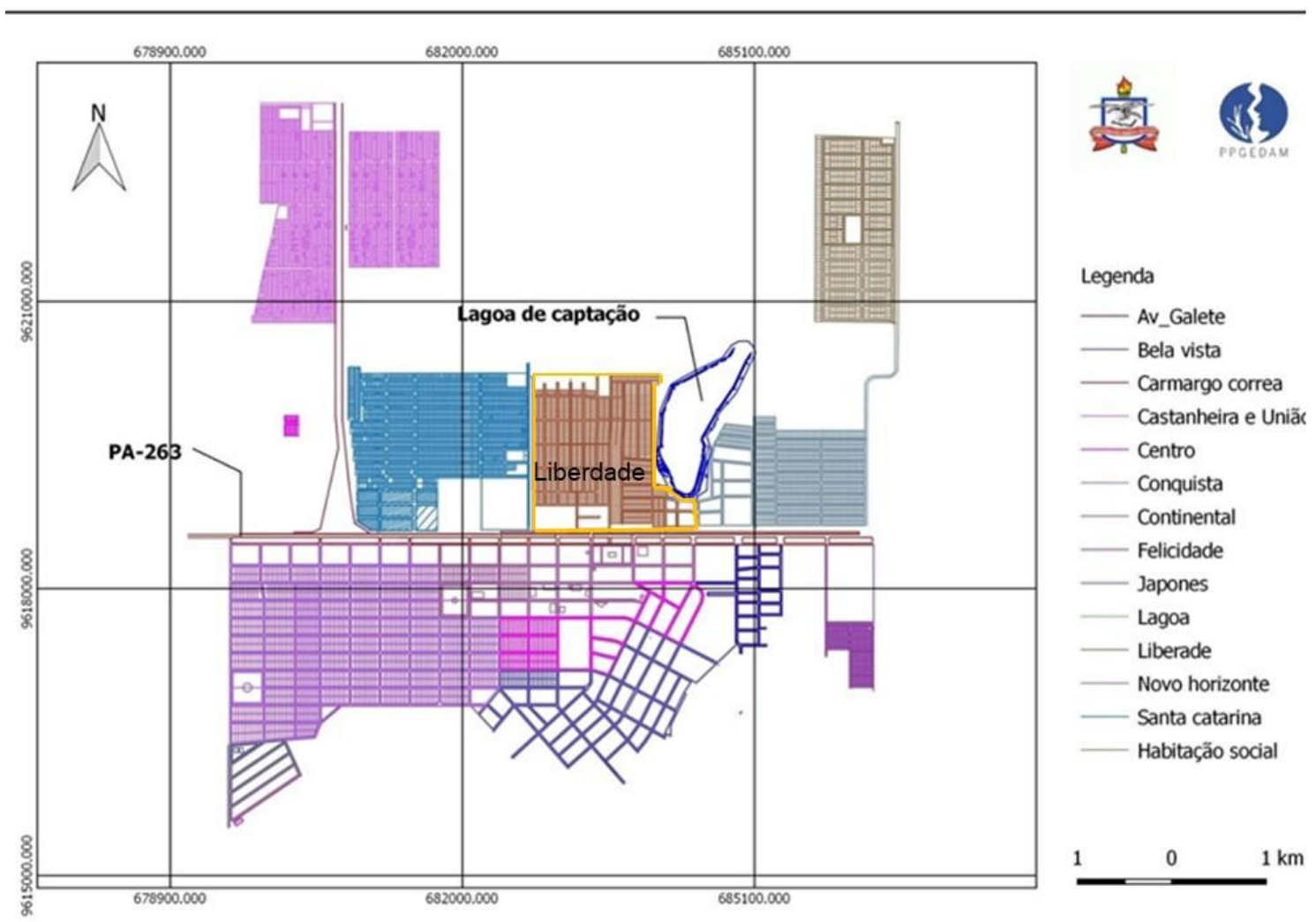

Figura 02. Localização do bairro Liberdade no município de Breu Branco, estado do Pará. Fonte: Silva, 2019. 


\section{Seleção de informantes e coletas de dados}

Para o desenvolvimento do trabalho recorreu-se ao procedimento de "busca ativa", mediante a realização de entrevista em âmbito domiciliar, com realização de entrevistas semiestruturadas, realizados pela pesquisadora ao informante (Albuquerque; Lucena, 2004), através de auxílio de um formulário com perguntas abertas, dando liberdade ao informante responder conforme o seu próprio raciocínio sobre conceitos acerca das espécies vegetais e seu emprego fitoterápico. Para a coleta de dados as entrevistas foram realizadas individualmente em visitas às residências dos participantes. As visitas foram realizadas no período de 14 março a 24 de abril de 2021, com a periodicidade semanal. Os formulários foram aplicados a 50 informantes (Pessoas de diferentes famílias e residências) na zona urbana do bairro Liberdade, de acordo com a disponibilidade da família, de maneira que não interferisse na rotina de suas atividades, procurando abranger pelo menos uma residência por família e informantes mulheres (mães) e homens (pais), os quais poderiam apresentar conhecimento considerável em relação ao uso das plantas medicinais e da fitoterapia. Todos os informantes foram entrevistados individualmente como recomendados por Phillips e Gentry (1993) para evitar que as respostas pudessem ser influenciadas por outra pessoa.

Os informantes incluídos possuíam idade mínima de dezoito anos, sem restrição de idade máxima, em casos de pessoas analfabetas, utilizouse a almofada do carimbo para obtenção da digital, ao qual substituiu a assinatura no TCLE, contudo, ocorreu a exclusão de pessoas com limitações de entendimento e fala. Considerando o presente momento relacionado à pandemia da COVID-19, ocorreu a implantação de medidas de segurança, para assegurar a saúde da pesquisadora e dos informantes. A pesquisadora encaminhou-se as entrevistas com a utilização de máscaras de tecido ou descartáveis, que foram trocadas a cada duas horas, aconselhou-se que os informantes também utilizassem máscaras. Estabeleceram-se os procedimentos de pelo menos um metro de distanciamento do informante e, higienização das mãos e dos materiais, conforme o protocolo de condutas de limpeza e desinfecção associadas ao COVID-19.

Na primeira etapa da entrevista, almejou-se conhecer o perfil dos informantes (Sexo, idade, escolaridade, estado civil, renda familiar, utilização

de unidades de saúde, município de origem e ocupação principal), métodos recorridos para tratar enfermidades, verificação do uso de plantas medicinais e difusão dos saberes. A segunda etapa buscou-se identificar os vegetais utilizados nos no combate às enfermidades, suas partes, modos de preparo, formas de uso e local de obtenção. A terceira etapa possuiu característica circunstancial, realizada de acordo com necessidades observadas pela entrevistadora.
Realizou-se o método de "caminhada na floresta" ou turnê guiada, consistindo na busca de informações com o informante de forma individual, pelas plantas citadas que são obtidas fora dos quintais, consideradas como "plantas do mato" (Alexiades, 1996).

Amostras botânicas foram identificadas no momento das entrevistas na companhia dos informantes. Quando não identificadas o material botânico foi coletado, processado, herborizado e posteriormente feita sua identificação através de literatura especializada e/ou chaves de identificação, evitando-se erros no momento da acurácia, através da morfologia externa do material. Além disso, foi realizado o registro fotográfico, anotação em caderno de campo das características das plantas. O sistema de classificação utilizado foi - APG III (2009) e os nomes científicos foram conferidos no site TROPICOS, do Missouri Botanical Garden.

\section{Análise de dados}

Para análise estatística os dados obtidos nas entrevistas e coletas foram compilados e analisados com base em um enfoque quanti e qualitativo, desenvolvido no programa Microsoft $\operatorname{Excel}^{\boxplus}(2007)$.

\section{Resultados e Discussão}

Perfil dos informantes

Foram entrevistados 50 informantes, sendo $88 \%$ do sexo feminino e $22 \%$ masculino, possuindo idades variando entre 18 a $30(20 \%), 31$ a $40(20 \%)$, 41 a $50(26 \%), 51$ a $60(22 \%)$ e, acima de 60 anos (12\%). Neste estudo foi possível observar que os informantes do sexo feminino possuíam maior hábito de consumo e conhecimento relativo às plantas medicinais. Resultado semelhante foi encontrado por Vásquez et al. (2010), aos quais as mulheres foram relacionadas ao uso, cultivo e preservação das tradições da medicina popular, no município de Manacapuru - AM. As faixas etárias foi outro fator que influenciaram o conhecimento dos saberes no uso das plantas medicinais. Os informantes com idade superior a 41 anos possuíram maior conhecimento no número e uso das plantas. Contrariamente aos resultados obtidos no presente trabalho, Badke et al. (2016), relataram que cerca de 1208 famílias moradoras da área urbana no noroeste do estado do Rio Grande do Sul, as quais utilizavam a Estratégia de Saúde da Família (ESF), os informantes idosos, acima de 60 anos, é que possuíam conhecimentos sobre o uso de plantas medicinais.

Considerando a escolaridade, houve predominância de participantes com ensino fundamental incompleto (45\%), seguido de ensino médio completo $(19 \%)$, ensino superior incompleto $(14 \%)$, ensino superior completo $(10 \%)$, ensino médio incompleto (8\%) e ensino fundamental completo (4\%). Evidencia-se o baixo nível de escolaridade entre os informantes, mostrando um índice de pouca conclusão do ensino fundamental 
em pessoas de maior idade. Segundo Ming e Amaral Junior (1995), isso pode colaborar na consolidação de repasse de informações de forma oral.

Em relação ao estado civil, casado(a) (50\%) sobressaiu-se entre os informantes, seguido por solteiro(a) (42\%), separado(a) (4\%), viúvo(a) (2\%) e outros (2\%). Freitas et al. (2012) também verificaram maior percentual de participantes casados em seu estudo, o que elevam a possibilidade de ter filhos, exigindo dos genitores a busca por soluções rápidas e práticas em saúde, como a utilização de plantas medicinais.

A análise da renda familiar demonstrou que a maioria recebe até um salário mínimo (80\%), dois salários (12\%) e mais de três salários (8\%). Nota-se a baixa condição financeira, associada à limitada escolaridade dos informantes. Em relação à ocupação dos informantes, destacaram-se, dona de casa $(30 \%)$, autônomo (24\%), aposentado (8\%), lavrador $(6 \%)$, professor $(4 \%)$, cozinheira, artesã, agente comunitário de saúde, secretário, auxiliar de serviços gerais, pedreiro, costureira, merendeira, estudante, atendente e manicure com $2 \%$ cada. Composição semelhante de entrevistados com predominância de mulheres repete-se em outros estudos etnobotânicos (Caon; Matias, 2013; Vasco dos Santos et al., 2018). De acordo com TorresAvilez et al. (2014) as diferenças entre os gêneros estão geralmente atreladas à ocupação ou papel social, fato que explica a predominância de entrevistadas nesta investigação, pois as mulheres permaneciam mais tempo nas residências executando atividades domésticas e o cuidado das crianças (Santos et al., 2010), sendo facilmente acessadas. Observou-se que as mulheres entrevistadas ficaram a vontade em falar sobre as plantas medicinais, relembrando facilmente as cultivadas em seus quintais ou em ambientes antropizados.

Quanto à região de origem dos informantes, destacaram-se maranhenses $(41 \%)$, seguidos dos paraenses $(39 \%)$ dos quais, 35\% nasceram no município de Tucuruí, 15\% em Breu Branco, 10\% em Santa Maria do Pará e Goianésia do Pará, 5\% em Castanhal, Moju, Belém, Portel, Santa Luzia e Cametá. Tocantinenses compõem $8 \%$ dos informantes, piauienses $4 \%$, além de capixaba, baiano, pernambucano e cearense correspondem cada um a $2 \%$ dos informantes. $O$ índice de imigração encontrado no bairro Liberdade, pode estar associado há grandes projetos que ocorreram na Amazônia no passado, como a construção Usina Hidrelétrica de Tucuruí, encontrada próxima ao município de Breu Branco. Estimasse que quase 540 mil pessoas migraram para o estado do Pará na década de 80 , destes aproximadamente $60 \%$ eram nordestinos, vindos principalmente do Estado do Maranhão (Cavalcante, 2005; Silva et al., 2018).

Entre os informantes, 90\% afirmaram fazer uso habitual das plantas medicinais ou pelo menos já tê-las utilizado em algum momento da sua vida. No que diz respeito à frequência do consumo das plantas medicinais, $47 \%$ declararam fazer o uso às vezes, $45 \%$ usa sempre e $8 \%$ nunca fez uso. Entretanto, do total de informantes entrevistados, $70 \%$ afirmaram que procuram as Unidades Básicas em Saúde (UBSs) em bairros vizinhos em casos de enfermidade, já que não há UBS no bairro Liberdade. Ainda constatou-se, a procura por farmácias e hospitais, correspondendo a 18 e 12\%, respectivamente, dos informantes.

Os informantes alegaram que os efeitos da utilização das plantas medicinais no combate as enfermidades foram ótimos (49\%), bons (38\%) e regulares (13\%). Ethur et al. (2011), constataram que no município de Itaqui no estado do Rio Grande do Sul, os informantes possuíam alto índice no consumo de plantas medicinais, os quais alegaram resultados positivos com o uso.

As plantas medicinais utilizadas pelos informantes foram obtidas de diversas fontes, entretanto, 59\% dos informantes adquiriram-nas em suas residências, obtidas nos próprios quintais, cultivadas diretamente no solo, em hortas suspensas com materiais em madeira ou vasos plásticos, além de materiais reutilizados. Plantas e receitas foram trocadas com facilidade entre os vizinhos e familiares, quando havia necessidade, reforçando os laços sociais. Os demais informantes (41\%), não cultivavam as plantas medicinais em suas residências, obtinham-nas através de amigos (41\%), supermercado (21\%), zona rural (20\%), feiras $(13 \%)$ e familiares $(5 \%)$. Esse resultado é contrastante com o estudo realizado por Feijó et al. (2013), no município de Ilhéus - BA, onde a maioria dos informantes obtiveram as plantas medicinais através de vizinhos ou parentes. De acordo com Amorozo (1996) nas sociedades rurais brasileiras, as plantas medicinais e receitas de uso são trocadas livremente entre os vizinhos quando há necessidade, reforçando, os laços sociais e contribuindo para o consenso cultural.

Em relação à origem do conhecimento na utilização de plantas medicinais, observou-se que o leito familiar $(76 \%)$ através da comunicação oral foi predominante na transmissão do saber, onde os pais, avós e cônjuges estiveram diretamente relacionados. Os amigos (18\%), livros, internet e médico ( $2 \%$ cada) tiveram também parcela de contribuição na transmissão dos saberes. A transmissão oral do conhecimento sobre o uso de plantas por sociedades humanas é praticada há gerações. Este padrão de transmissão oral e de dominância feminina sobre o conhecimento de uso das plantas medicinais têm se repetido em estudos etnobotânicos (Costa; Mayworm, 2011).

\section{Levantamento etnobotânico}

As plantas medicinais foram distribuídas em 39 espécies, pertencentes a 25 famílias botânicas. A família Lamiaceae apresentou o maior número de espécies citadas, com cinco espécies mencionadas, seguido das famílias Apiaceae, Malvaceae e Poaceae, com três espécies cada, e as famílias Asteraceae, Euphorbiaceae, Fabaceae, 
Zingiberaceae com duas espécies. As demais famílias apresentaram uma única espécie representante e foram as seguintes: Acanthaceae, Adoxaceae, Aamaranthaceae, Amaryllidaceae, Annonaceae, Bignoniaceae, Caricacea, Costaceae, Lauraceae, Meliaceae, Myrtaceae, Moraceae, Portulacaceae, Rutuceae, Xanthorrhorarceae (Figura 3).

Apesar da representatividade da família Lamiaceae em estudos etnobotânicos, as demais famílias com maior número de representantes tais como Apiaceae, Malvaceae e Poaceae possuem poucos relatos em levantamentos realizados nas regiões Sul e Centro-oeste, tendo em vista que, as famílias como Euphorbiaceae, Fabaceae, Asteraceae possuíram maiores citações entre os informantes das regiões Sul e Centro-oeste (Battisti et al., 2013; Cunha; Bortolotto, 2011;). Presume-se assim, que as famílias Lamiaceae, Apiaceae, Malvaceae e Poaceae, possuem características particulares que tornaram-se atrativos para a população no presente estudo (Figura 3).

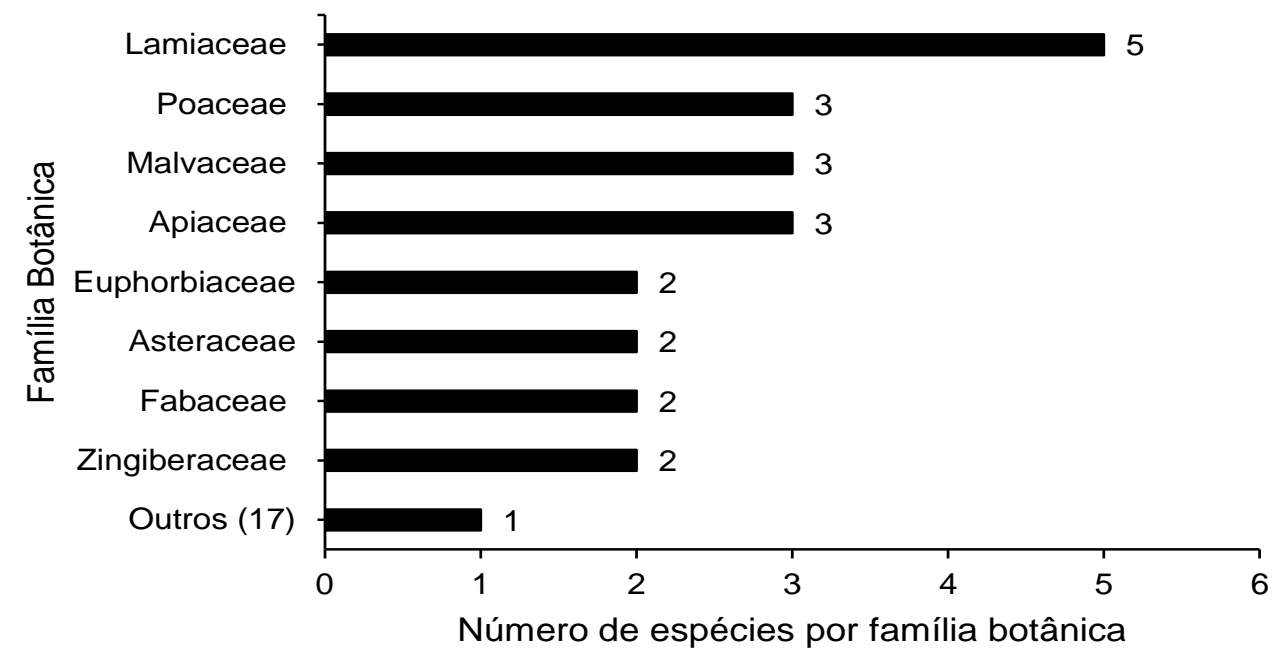

Figura 03. Número de espécies por família botânica citada pelos informantes do bairro Liberdade, no município de Breu Branco, estado do Pará.

A predominância de uso de espécies de uma mesma família, como o ocorrido no bairro Liberdade, principalmente para a família Lamiaceae seguidas da Apiaceae, Malvaceae e Poaceae demonstrou possuir maior distribuição local onde foi realizado o estudo, principalmente devido o cultivo, evidenciando potencial medicinal da família, visto que foram utilizadas com maior frequência. Zucchi et al. (2013), em um levantamento etnobotânico no município de Ipameri - GO, também constataram que a família Lamiaceae obteve maior representatividade entre as famílias informadas. Costa et al. (2017), em um estudo de identificação das espécies vegetais na zona rural, do município de Parauapebas - PA, verificaram maior ocorrência na frequência das famílias, Malvaceae (142) a Musaceae e a Lamiaceae (80 cada), Arecaceae (77), a Euphorbiaceae (70), Poaceae (54) e Anacardiaceae (53).

As espécies com maior número de citações pelos informantes foram Melissa officinalis (Erva-cidreira) com 22 citações, seguido de Cymbopogon atratus (Capim santo) e Plectranthus barbatus (Boldo) com 14 citações cada e, Mentha spicata (Hortelã) com 13 citações (Figura 4). A ervacidreira, capim santo, boldo e hortelã são comumente citadas em diferentes regiões do país (Lopes et al., 2015).
Melissa officinalis (Erva-cidreira) foi mencionada por 14\% (22 ocorrências) dos informantes, é uma planta perene e herbácea da família Lamiaceae, de origem asiática. É uma planta aromática de 30 a $100 \mathrm{~cm}$ de altura, com folhas rugosas, e flores de coloração branca, rosa e amarela que florescerem no verão (Brasil, 2019). A ação medicamentosa da erva-cidreira é amplamente conhecida, pelo bioativo calmante, antisséptico, anti-inflamatório, diurética dos óleos essenciais, ocorrendo aproveitamento da indústria farmacêutica e cosmética (Menezes, 2012).

Cymbopogon atratus (Capim santo) foi citada por $9 \%$ (14 ocorrências) dos informantes, é pertencente à família Poaceae, também denominada gramínea apresenta folhas laminares, definidas como lineares. O gênero Cymbopogon é constituído por planta perene, de origem asiática que tende a ser cultivada em climas tropicais e subtropicais (Gomes; Negrelle, 2003).

Plectranthus barbatus (Boldo) foi citada por 9\% (14 ocorrências) dos informantes, é uma planta herbácea subarbustiva, aromática e perene da família Lamiaceae. Possui altura variável de 1 a 2 metros, com folhas aveludadas, e flores de cor roxa (Junior; Michalak, 2014). É oriunda da Ásia, especificamente da Índia, ao chegar ao Brasil popularizou-se, sendo cultivada em todo território nacional. Comumente é empregado a problemas 
estomacais, principalmente relacionadas ao fígado (Grandi, 2014).

Mentha spicata (Hortelã) foi citada por $8 \%$ (13 ocorrências) dos informantes, é uma planta aromática, que pertence família Lamiaceae. E uma espécie perene de odor característico adocicado, possuindo altura entre 0,4 a 1,30 metros e suas flores geralmente são brancas disposta em inflorescências (Grandi, 214). O gênero Mentha é cultivado em todo o planeta decorrente o alto valor comercial, mas de origem natural vinda da Europa e Ásia, suas propriedades terapêuticas relacionadas ao tratamento de resfriados, problemas estomacais e antialérgicas, são conhecidos desde a antiguidade pelos gregos e egípcios (Anwar et al., 2019).



Figura 04. Espécies citadas como medicinais por informantes do bairro Liberdade, no município de Breu Branco, estado do Pará.

O hábito de crescimento botânico predominante foi o herbáceo (61\%), seguido do arbóreo (18\%), arbustivo (13\%) e trepador/liana (8\%) (Figura 5). A preferência por plantas medicinais herbáceas pode estar relacionada com a facilidade de cultivo de plantas de pequeno porte na zona urbana, aos quais as residências podem dispor de pouco espaço livre para plantio. Em estudos etnobotânicos, as espécies herbáceas foram mais citadas quando comparada com os demais hábitos de crescimento. A facilidade de coleta foi mencionada como uma tendência que promoveu maior cultivo e consumo das espécies (Aguiar; Barros, 2012; Silva et al., 2012).

Entre as partes das plantas, a folha foi a mais utilizada no preparo das receitas da medicina 
popular (56\%) seguido da semente (19\%), flor $(11 \%)$, caule $(8 \%)$ e raiz $(6 \%)$ (Figura 6$)$. A utilização das folhas pelos informantes se deu provavelmente pela conservação da espécie (manutenção de cultivo) e melhor aproveitamento da planta, tendo em vista que a retirada de partes do caule ou da raiz pode inibir o crescimento da planta. Por se tratar da região amazônica a tendência da utilização das folhas para a preparação de remédios é um habito costumeiro, considerando que as muitas plantas são cultivadas e colhidas nas próprias residências, e as folhas consumidas não passam pelo processo de armazenamento e compra (Martins et al., 2013;).

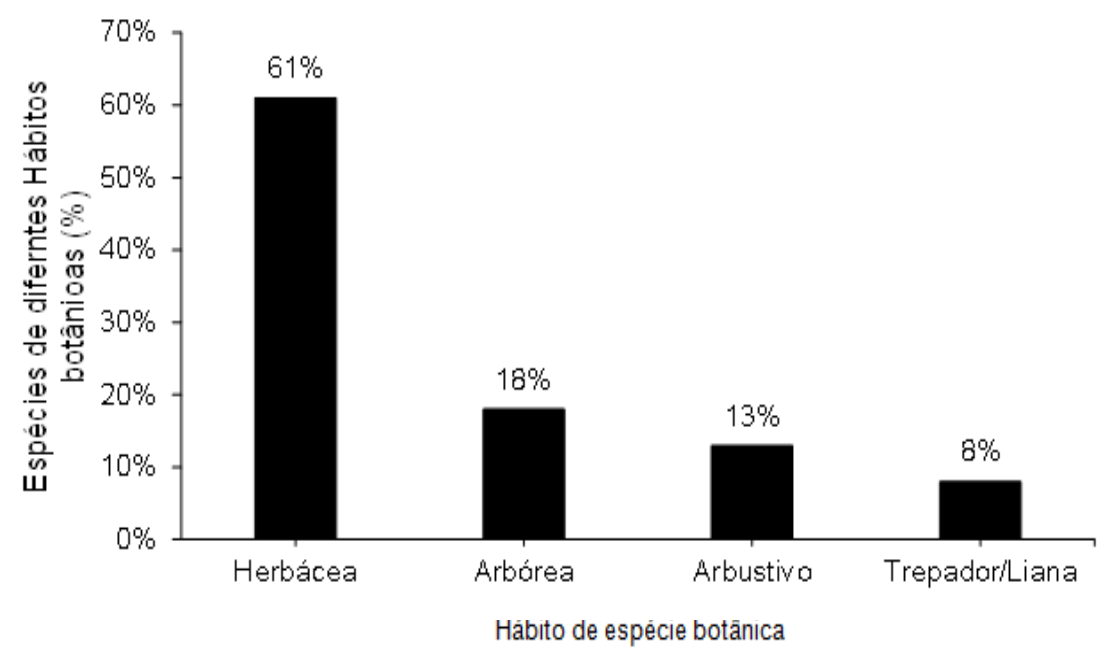

Figura 05. Hábito de crescimento das espécies citadas por informantes do bairro Liberdade, no município de Breu Branco, estado do Pará.



Figura 06. Partes vegetais utilizadas como medicinais das plantas citadas por informantes do bairro Liberdade, no município de Breu Branco, estado do Pará.

O modo de preparo das plantas medicinais foi diverso, sendo o mais utilizado, o chá por decocção (43\%), seguido do chá por infusão (42\%), demonstrando que a preparação de chás tornou-se o preferido pelos informantes. As outras formas de preparo apresentaram menores porcentagens, tais como óleo (4\%), inalação, lavagem, emplasmo, macerado ( $2 \%$ cada) e, pó, xarope e in natura $(1 \%$ cada) (Figura 7). Em estudos similares, a preparação de chás foi apontada pelos informantes como principal forma de consumo (Cordeiro; Félix, 2014; Ribeiro et al., 2014). O consumo de chás tornou a principal opção decorrente da variabilidade de partes botânicas que podem ser utilizadas, preço geralmente acessível e rapidez do preparo. Apesar do chá por decocção ser associado ao cozimento de partes mais duras, como raízes e cascas, em muitos estudos etnobotânicos os chás por decocção também têm sido empregados em partes botânicas mais sensíveis, como as folhas (Barbosa et al., 2019).

De acordo com as informações obtidas nas entrevistas, foi possível organizar as diferentes indicações terapêuticas citadas pelos informantes em dezoito categorias de doenças, sintomas e utilidades (Figura 8). O maior número de citações de 
doenças, sintomas e utilidades indicadas referem-se a sintomas inflamatórios (inflamação de garganta, ferida e corte) com 19 citações (representando $23,3 \%$ das enfermidades), seguidos por 11 citações de consumo alimentar (representando 16,3\%), evidenciando o uso dos chás como substituição de determinadas bebidas como o café, e por 8 citações (representado $7 \%$ das enfermidades) relacionada a gripe.

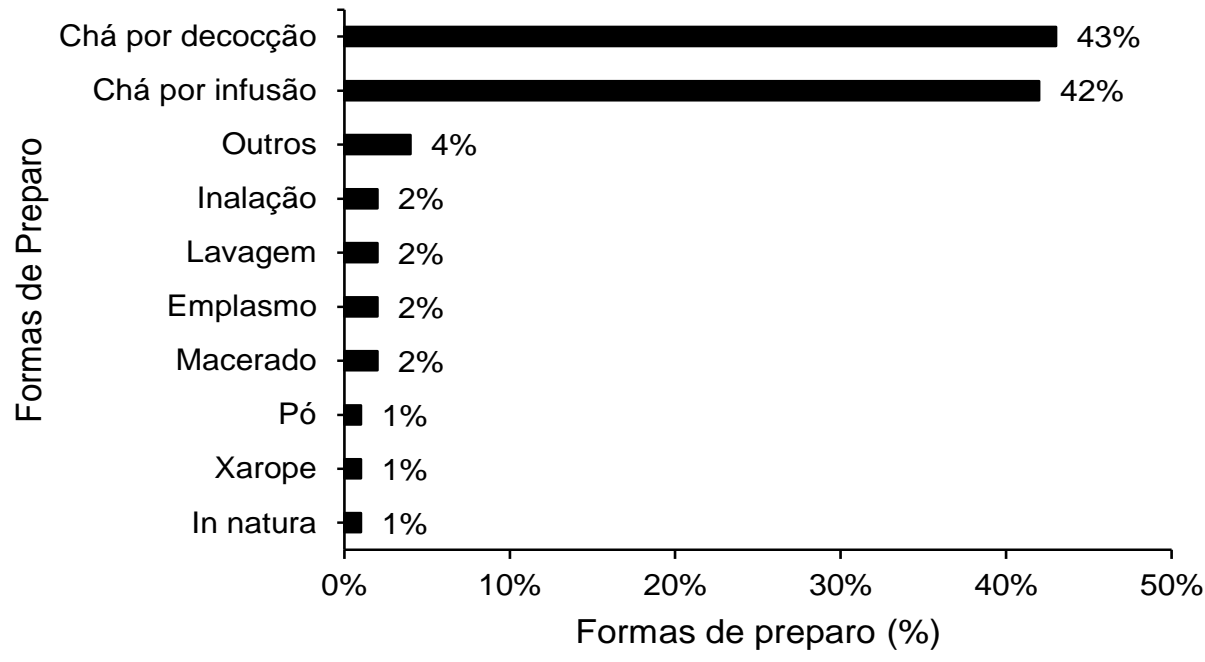

Figura 07. Formas de preparo das plantas medicinais dos informantes do bairro Liberdade, no município de Breu Branco, estado do Pará.

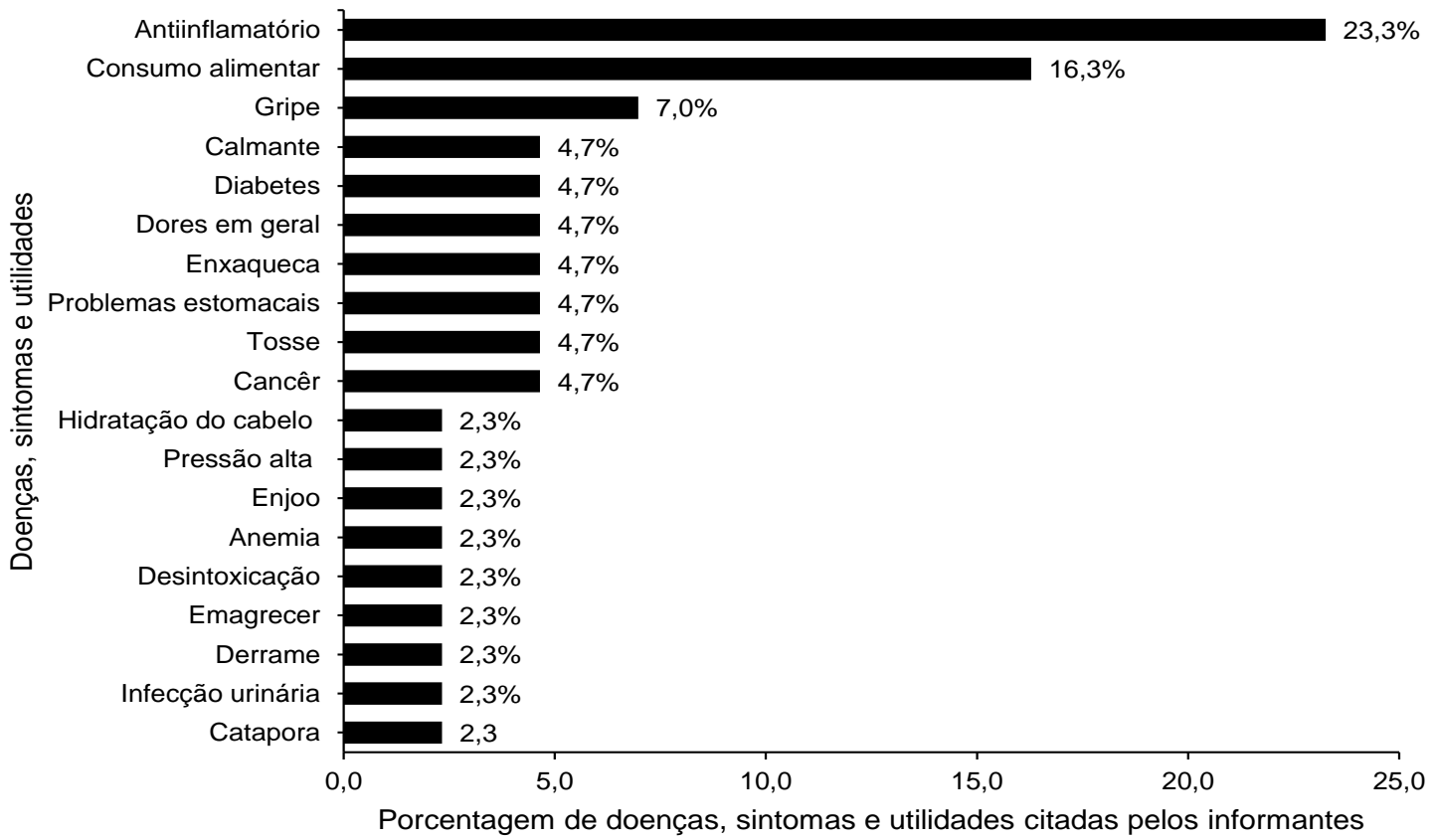

Figura 08. Doenças, sintomas e utilidades citados pelos informantes do bairro Liberdade, no município de Breu Branco, estado do Pará.

Em estudos realizados nos municípios paraenses de Abaetetuba, Uruará e Belém constataram-se que as plantas mencionadas como andiroba, copaíba, pariri, amor crescido, sabugueiro, mastruz, estão relacionadas à bioativos de ação antiinflamatório das espécies. Os índices de afecções inflamatórias estão associados às dores de gargantas, oriunda de afecções do sistema respiratório e ferimentos ocasionados no cotidiano, como acidentes em veículos automotores. $\mathrm{O}$ que também explica as citações a gripes (Leal et al., 2019). Enquanto, a utilização de plantas no consumo alimentar, relaciona-se a diminuição calórica, ocasionada pela tendência de diminuição de bebidas industriais. 
Apesar do fortalecimento do sistema imunológico para diminuir possíveis complicações resultantes da COVID-19, não destacar-se como o principal uso das plantas citadas na Figura 08, evidenciou-se durante as entrevistas cinco menções com esse propósito ocorridas no último ano com a utilização de boldo e açafrão. Segundo os informantes, o uso iniciou como uma profilaxia natural, pretendendo a diminuição do consumo de medicamentos industrializados. Silva et al. (2020) confirmaram que durante a pandemia da COVID-19 houve maior procura por tratamento antivirais alternativos, decorrentes do incentivo do isolamento social, ao qual diminuiu a procura por farmácias e unidades de saúde, tendo em vista, que durante um determinado período apenas casos suspeitos de corona vírus eram atendidos nos hospitais. Em estudos relacionados ao uso de plantas medicinais para o tratamento da COVID-19, relata-se que a crescente desvalorização dos medicamentos disponíveis no mercado, e a carência de vacinas até então mencionado no presente estudo, ampliaram o uso da medicina popular. Porém, o uso indiscriminado das plantas medicinais sem a devida indicação ou comprovação de eficácia, torna-se uma problemática emergente (Braga; Silva, 2021).

\section{Conclusões}

O presente estudo permitiu verificar que os informantes do bairro Liberdade possuem conhecimentos e recorrem a uso de plantas medicinais, como uma forma de tratar suas enfermidades mais frequentes, sendo elas relacionadas a sintomas inflamatórios, utilizando principalmente as folhas, geralmente para a preparação de chás. As espécies mais utilizadas como medicinais foram: Melissa officinalis, Plectranthus barbatus, Cymbopogon atratus e Mentha spicata, demonstrando a importância dessas espécies para futuros estudos farmacológicos, possibilitando que o conhecimento popular seja corroborado pelo conhecimento científico.

Os informantes em sua maioria preferiram a utilização das plantas medicinais ao invés de fármacos. Neste cenário, tornam-se importante a realização de projetos interdisciplinares nos quais ocorra o diálogo entre os setores públicos, as ciências da saúde e sociais, almejando fortalecer e difundir os saberes médicos encontrados, bem como, a conservação da flora medicinal, preservando, assim, a identidade médica da comunidade do bairro Liberdade.

\section{Referências}

AGUIAR, L. C. G. G., BARROS, R. F. M.. Plantas medicinais cultivadas em quintais de comunidades rurais no domínio do cerrado piauiense (Município de Demerval Lobão, Piauí, Brasil). Revista Brasileira de Plantas Medicinais, v. 14, n. 3, p.419-434, 2012. https://doi.org/10.1590/S1516-05722012000300001.
ALBUQUERQUE, U. P., ANDRADE, L. H. C. Conhecimento botânico tradicional e conservação em uma área de caatinga no estado de Pernambuco, Nordeste do Brasil. Acta Botanica Brasilica, v. 16, n. 3, p. 273-285, 2002. https://doi.org/10.1590/S0102-33062002000300004.

ALEXIADES, M. Collecting Ethnobotanical Data: Anintroduction to basic concept sand techniques. In: Selected Guidelines for Ethnobotanical Research: A field

manual. The New York Botanical Garden, Nova York, v. 10, p. 53-94, 1996.

ALBUQUERQUE, U. P., LUCENA, R. F. P. (Org). Métodos e técnicas na pesquisa etnobotânica. Recife, Livro Rápido / NUPPEA. 2004.

AMOROZO, M. C. M.; GÉLY, A.L. Uso de plantas medicinais por caboclos do Baixo Amazonas. Boletim do Museu Paraense Emilio Goeldi, v. 4, p. 47-131, 1988.

ANGIOSPERM PHYLOGENY GROUP. An update of the phylogeny group classification for the orders and families of flowering plants: APG III. Botanical Journal of the Linnean Society, v. 161, p. 105-121, 2009.

8339.2009.00996.x.

ANWAR, F., ABBAS, A., MEHMOOD, T., GILANI, A. H., REHMAN, N. Mentha: A genus rich in vital nutra-pharmaceuticals - A review. Phytotherapy Research, Hoboken, v. 33, p. 2548-2570, 2019. https://doi.org/10.1002/ptr.6423.

BADKE, M. R., SOMAVILLA, C. A., HEISLER, E. V., ANDRADE. A., BUDÔ, L. M. D., GARLET, T. M. B. Saber popular: uso de plantas medicinais como forma terapêutica no cuidado à saúde. Revista de Enfermagem da UFSM, Santa Maria, v. 6, n. 2, p. 225-234 https://doi.org/10.5902/2179769217945.

2016.

BARBOSA, C. S., SCUDELLER, V. V., FERREIRA, S. A. N., BONATTO, E. C. S., PINTO, E. O. S. Plantas medicinais cultivadas em quintais no bairro de São Raimundo, da cidade de Manaus, AM. Revista Terceira Margem Amazônia, v. 4, n. 12, p.122-141, 2019. https://doi.org/10.36882/25254812.2019v4i12p\%25p.

BATTISTI, C., GARLET, T. M. B., ESSI, L., HORBACH, R. K., ANDRADE. A., BADKE, M. R. Plantas medicinais utilizadas no município de Palmeira das Missões, RS, Brasil. Revista Brasileira de Biociências, Porto Alegre, v. 11, n. 3, p. 338-348, 2013.file:///C:/Users/USER/Downloads/2457-169411-PB.pdf.

BRAGA, J. C. B., SILVA, L. R. Consumo de plantas medicinais e fitoterápicos no Brasil: perfil de consumidores e sua relação com a pandemia de 
COVID-19. Brazilian Journal of Health Review, v.4, n.1, p.3831-3839, 2021 . https://doi.org/10.34119/bjhrv4n1-303.

BRASIL. Ministério da Saúde. Conselho Nacional de Saúde. Resolução №466 de 12 de dezembro de 2012. Brasília, DF, 14 jun. 2013.

BRASIL. Farmacopeia Brasileira. Brasília: Agência Nacional de Vigilância Sanitária - ANVISA, 2019. Disponívelem:<https://www.gov.br/anvisa/ptbr/assun tos/farmacopeia/farmacopeiabrasileira/arquivos/798 9json-file-1>. Acesso em: 21 mai. 2021.

CAVALCANTE, F. C.O processo migratório na Amazônia vinculado à mobilidade pelo trabalho - 0 caso da UHE de Tucuruí. In: ENCONTRO DE GEÓGRAFOS DA AMÉRICA LATINA, 5., 2005, São Paulo. Anais... São Paulo: Universidade de São Paulo, 2005. p.3345-3360.

COAN, C. M., MATIAS, T. A. utilização das plantas medicinais pela comunidade indígena de Ventarra Alta-RS. Revista de Educação do Ideau, v. 8, n. 18, p.

$1-13$ 2013.http://revista2.grupointegrado.br/revista/index. php/sabios/article/view/958/571.

CORDEIRO, J. M. P., FELIX, L. P. Conhecimento botânico medicinal sobre espécies vegetais nativas da caatinga e plantas espontâneas no agreste da Paraíba, Brasil. Revista Brasileira de Plantas Medicinais, v.16, n.3, p.685-692, 2014. https://doi.org/10.1590/1983-084x/13 077.

COSTA, V. P., MAYWORM, M. A. S. Plantas medicinais utilizadas pela comunidade do bairro dos Tenentes - município de Extrema, MG, Brasil. Revista Brasileira de Plantas Medicinais, Botucatu, v.13, n.3, p.282-292, 2011. https://doi.org/10.1590/S1516-05722011000300006.

COSTA, G. C., MOURA, N. D. S., FARIAS, A. K. D., ALHO, E. A., JUCOSKI, G. O. Caracterização socioeconômica e levantamento de espécies vegetais em quintais agroflorestais da zona rural do município de Parauapebas, Pará. Agroecossistemas, v. 9, n. 1, p. 199-211, 2017. https://periodicos.ufpa.br/index.php/agroecossistem as/article/viewFile/4653/4399.

CUNHA, S. A., BORTOLOTTO, I. M. Etnobotânica de Plantas Medicinais no Assentamento Monjolinho, município de Anastácio, Mato Grosso do Sul, Brasil. Acta Botanica Brasilica, v. 25, n. 3, p. 685-698, set. 2011. $\underline{3062011000300022}$.

ETHUR, L. Z. JOBIM, J. C., RITTER, J. G., OLIVEIRA, G., TRINDADE, B. S. comércio formal e perfil de consumidores de plantas medicinais e fitoterápicos no município de Itaqui - RS. Revista Brasileira de Plantas Medicinais, Botucatu, v. 13, n.
2, p. 121-128, 2011. https://doi.org/10.1590/S151605722011000200001.

FEIJÓ, E. V. R. S., PEREIRA, A. S., SOUZA, L. R., SILVA, L. A. M., COSTA, L. C. B. Levantamento preliminar sobre plantas medicinais utilizadas no bairro Salobrinho no município de llhéus, Bahia. Revista Brasileira de Plantas Medicinais, v. 15, n. 4, p. 595-604, 2013. https://doi.org/10.1590/S1516$\underline{05722013000400017 .}$.

GANDOLFO, E. S., HANAZAKI, N. Etnobotânica e urbanização: conhecimento e utilização de plantas de restinga pela comunidade nativa do distrito do Campeche (Florianópolis, SC). Acta Botânica Brasilica, Brasília, v. 25, n. 1, p.168-177, 2011. https://doi.org/10.1590/S0102-33062011000100020.

GOMES, E. C., NEGRELLE, R. R. B. Cymbopogon citratus (D.C.) Stapf: aspectos botânicos e ecológicos. Visão Acadêmica, v. 4, n. 2, p. 137-144, 2003. http://dx.doi.org/10.5380/acd.v4i2.534.

GRANDI, T. S. M. (Org). Tratado das plantas medicinais mineiras, nativas e cultivadas. Belo Horizonte, Adaequatio Estúdio, 2014.

INSTITUTO BRASILEIRO DE GEOGRAFIA E ESTATÍSTICA - IBGE. Breu Branco. Brasília, DF, IBGE, $2017 . \quad$ Disponível em: https://cidades.ibge.gov.br/brasil/pa/breubranco/pan orama. Acesso em: 19 dez. 2020.

JUNIOR, A. A. S., MICHALAK, E. (Org). O Éden de Eva. Florianópolis, Epagri, 2014.

LEAL, J. B., SILVA, M. M., COSTA, J. M., ALBUQUERQUE, L. C. S., PEREIRA, M. G. S., SOISA, R. L. Etnobotânica de plantas medicinais com potencial antiinflamatório utilizadas pelos moradores de duas comunidades no município de Abaetetuba, Pará. Biodiversidade, n. 18, v. 3, p.110125 ,

2019.

file:///C:/Users/USER/Downloads/9410Texto\%20do

\%20Artigo-33454-1-10-20191123.pdf.

LOPES, M., NOGUEIRA, I. S., OBICl, S., ALBIEIRO, A. L. M. Estudo das plantas medicinais, utilizadas pelos pacientes atendidos no programa "Estratégia saúde da família" em Maringá/PR/Brasil. Revista Brasileira de Plantas Medicinais, v. 17, n. 4, p. 702-706, 2015. https://doi.org/10.1590/1983$\underline{084 X / 12173 .}$.

MARTINS, A. G., ROSÁRIO, D. L., BARROS, M. N., JARDIM, M. Levantamento etnobotânico de plantas medicinais, alimentares e tóxicas da llha do Combu, município de Belém, Estado do Pará, Brasil. Revista Brasileira de Farmácia, v. 86, n. 1, p.21-30, 2005.

MARTINS, W. M. O., PAIVA, F. S., B. C. A. Etnoconhecimento de plantas de uso medicinal na microrregião do Vale do Juruá, Acre, Brasil. 
Enciclopédia Biosfera, Centro Científico Conhecer, v.9, n.16, p. 2540-2547, 2013. https://www.conhecer.org.br/enciclop/2013a/miltidisc iplinar/etnoconhecimento.pdf.

MENEZES, Camila Pinheiro de. Atividade antifúngica In Vitro do óleo essencial de Melissa officinalis L. (Erva Cidreira) sobre Cladasporium carrionii. 2012. 124 f. Dissertação (Mestrado em Produtos Naturais e Sintéticos Bioativos) Universidade Federal da Paraíba, João Pessoal, 2012.

MING, L. C. A Etnobotânica na recuperação do conhecimento popular. In: ENCONTRO INTERNACIONAL SOBRE AGROECOLOGIA E DESENVOLVIMENTO RURAL SUSTENTÁVEL, 2001, Botucatu. Anais do Encontro Internacional sobre Agroecologia e Desenvolvimento Rural Sustentável. Botucatu: UNESP, 2001. p. 3.

PHILLIPS, O., GENTRY, A. H. The Useful Plants of Tambopata, Peru: II. Additional Hypothesis Testing in Quantitative Ethnobotany. Economic Botany, v. 47, n. 1, p.15-32, jan. 1993. https://www.jstor.org/stable/4255480?origin=JSTORpdf.

PREFEITURA MUNICIPAL DE BREU BRANCO. Lei n. 415 de 02 de setembro de 2006. Plano diretor do município de Breu Branco. Breu Branco, Consórcio Engevix-Themag, 2006

RIBEIRO, D. A., MACÊDO, D. G., OLIVEIRA, L. G. S., SARAIVA, M. E., OLIVEIRA, S. F., SOUZA, M. M. A., MENEZES, I. R. A.. Potencial terapêutico e uso de plantas medicinais em uma área de Caatinga no estado do Ceará, nordeste do Brasil. Revista Brasileira de Plantas Medicinais, Campinas, v.16, n.4, p.912-930, dez. 2014. https://doi.org/10.1590/1983-084X/13 059.

ROCHA, J. A., NEFFA, E.; LEANDRO, L. A. Contribuição da Etnobotânica na elaboração de políticas públicas em meio ambiente - um desafio na aproximação do discurso à prática. Ambiência, v. 10, n. 1 p.43-64, 2014. http://nuredam.com.br/files/artigos/periodicos/2014, \%20ROCHA \%20NEFFA \%20LEANDRO.\%20A\%2 0contribui\%C3\%A7\%C3\%A30\%20da\%20etnobot $\%$ C3\%A2nica.pdf.

ROCHA, J. A., BOSCOLO, O. H.; FERNANDES, L. R. R. M. V. Etnobotânica: um instrumento para valorização e identificação de potenciais de proteção do conhecimento tradicional. Interações, v. $16, \quad$ n. $1, \quad$ p.67-74, 2015. https://doi.org/10.1590/151870122015105.

SANTOS, M. L., ARAÚJO, E. M., BATISTA, A. R. Plantas Medicinais Usadas pelos Índios Kambiwá Ibimirim - PE. Revista Brasileira de Informações Científicas, v. 1, n. 1, p. 78-85, 2010. https://silo.tips/download/plantas-medicinais-usadaspelos-indios-kambiwa-ibimirim-pe.

SILVA, S., ANSELMO, M,. G. V., DANTAS, W. M., ROSA, J. H., NUNES, E. N., SOARES, J. P., ALVES, C. A. B. Conhecimento e uso de plantas medicinais em uma comunidade rural no município de Cuitegi, Paraíba, Nordeste do Brasil. Gaia Scientia, v. 8, n. 1, p. 248 - 265, 2014.https://periodicos.ufpb.br/ojs2/index.php/gaia/a rticle/view/21256.

SILVA, N. C. B., DELFINO REGIS, A. C., ESQUIBBEL, M. A., SANTOS, J. E. S., ALMEIDA, M. Z. Uso de plantas medicinais na comunidade quilombola da Barra II - Bahia, Brasil. Boletín Latino americano y del Caribe de. Plantas Medicinales y Aromáticas, v.11, n. 5, p.435-453, 2012. https://www.redalyc.org/pdf/856/85624131006.pdf.

SILVA, Wagner Luiz Gonçalves da. Cartografia da dinâmica urbana de uso e ocupação do solo no município de Breu Branco-PA. 2019. $79 \mathrm{f}$. Dissertação (Gestão dos Recursos Naturais e Desenvolvimento Local na Amazônia) Universidade Federal do Pará, Belém, 2019.

SILVA, J. V. F., JÚNIOR, F. P. S., SILVA, A. C. Migração e colonização da transamazônica na obra de Odette de Barros Mott. Nova Revista Amazônica, v. $6, \quad$ n. $2, \quad$ p. 103-122, 2018. http://dx.doi.org/10.18542/nra.v6i2.6194.

SILVA, F. G. C., BORGES, A. L. T. F., OLIVEIRA, J. V. L., PRATA, A. P. N., PORTO, I. C. C. M., ALMEIDA, C. A. C.; SOUSA, J. S., FREITAS, J. D.; OLIVERIA-FILHO, A. D., REIS, F. M. P., OLIVEIRA, R. A. G.; SILVA, S. A. S.; NASCIMENTO, T. G Alimentos, nutraceuticos e plantas medicinais utilizados como prática complementar para 0 coronavírus (COVID-19) sintomas: uma revisão. 2020. https://doi.org/10.1590/SciELOPreprints.317.

TORRES-AVILEZ, W., NASCIMENTO, A. L. B., CAMPOS, L. Z. O., SILVA, F. S., ALBUQUERQUE, U. P. Gênero e Idade. In: ALBUQUERQUE, U. P. (Org.). Introdução à Etnobiologia. Recife, PE: NUPEEA, 2014. p. 169-174.

TROPICOS. Tropicos.org. Missouri Botanical Garden. Disponível em <http://www.tropicos.org>. Acesso em: 20 jun. 2021.

VASCO DOS SANTOS, D. R., SANTOS, J. V., ANDRADE, W. M., SANTOS LIMA, T. M., LIMA, L. N., DIAS LIMA, A. G., ANDRADE, M. J. G., VANIER SANTOS, M. A., MOURA, G. J. B., NUNES, E. S. Plantas antiparasitárias utilizadas pelos indígenas Kantarur-e-Batida (NE- Brasil): Etnobotânica e riscos de erosão dos saberes locais. Ambiente e Sociedade, v. 21, p. 1-20, 2018.https://www.scielo.br/j/asoc/a/YWYjZcRzQJ9k W8t8W8yVD3y/?format=pdf\&lang=pt. 
VÁSQUEZ, S. P. F., MENDONÇA, M. S., NODA, S. N. Etnobotânica de plantas medicinais em comunidades ribeirinhas do Município de Manacapuru, Amazonas, Brasil. Acta Amazônica, v.44, n. 04 , p. 457-472, dez. 2014.https://www.scielo.br/j/aa/a/VygsxBjLYBDf8Nc WBHGYF8Q/?lang=pt\&format=pdf.

ZUCCHI, M. R., OLIVEIRA JUNIOR, V. F., GUSSONI, M. A., SILVA, M. B., SILVA, F. C., MARQUES, N. E. Levantamento de plantas medicinais na cidade de Ipameri - GO. Revista Brasileira de Plantas Medicinais, v.15, n.2, p. 273279 , 2013. https://doi.org/10.1590/S151605722013000200016. 